\title{
From Mathematical Fictionalism to Truth-Theoretic Fictionalism
}

BRADLEY ARMOUR-GARB

University at Albany

JAMES A. WOODBRIDGE

University of Nevada, Las Vegas

In this paper, we argue that if Stephen Yablo (2005) is right that philosophers of mathematics ought to endorse a fictionalist view of number-talk, then there is a compelling reason for deflationists about truth (henceforth, T-deflationists) to endorse a fictionalist view of truth-talk. More specifically, our claim will be that, for T-deflationists, Yablo's argument for mathematical fictionalism can be employed and mounted as an argument for truththeoretic fictionalism.

Yablo's own fictionalist account of number-talk is what he calls "figuralism", a subspecies of pretense-involving fictionalism, which is a non-error-theoretic species of the genus philosophical fictionalism, one that allows that utterances can be true even if their operation involves fiction. Now, while Yablo's considerations - the ones with which we will be concerned, in any case-are ultimately presented in the service of motivating his particular pretense-involving fictionalist account of number-talk, we can and should take these considerations to support mathematical fictionalism more generally. Accordingly, while we will be concerned with Yablo's argument for the kind of mathematical fictionalism he endorses, the argument that we will present, in support of T-deflationists endorsing fictionalism about truth-talk, is not intended to support a particular pretense-involving fictionalist account of truth-talk. To belabor the point, what we will show is that if Yablo's considerations in favor of some sort of fictionalism about mathematics compel (and, for what follows, we will assume that they do), then we have a reason for 
thinking that T-deflationists ought to endorse or adopt some sort of fictionalism about truth-talk. ${ }^{1}$

The plan is as follows. $\S 1$ discusses mathematical fictionalism, with special interest in Yablo's fictionalist view of mathematical discourse. §2 introduces the key elements of deflationism and explains T-deflationism in particular. $\$ 3$ explains why T-deflationists ought to endorse fictionalism about truth-talk; $\$ 4$ considers, and responds to, some objections to our chief claim; and $\$ 5$ concludes.

\section{Yablo's Mathematical Fictionalism}

Before turning to Yablo's brand of mathematical fictionalism, a few words on fictionalism. It is useful to distinguish the philosophy of fiction from philosophical fictionalism. The former is concerned with issues and questions that are about certain aspects of fiction, such as whether fictional characters (e.g., Sherlock Holmes) exist, about the aletheic status of claims from a work of fiction or claims about a work of fiction's content, etc. By contrast, rather than analyzing philosophical issues that are about certain aspects of fiction itself, philosophical fictionalism employs the notion of fiction in order to resolve certain philosophical puzzles or paradoxes that arise from some putatively problematic discourse. ${ }^{2}$ Our focus in this section will be on philosophical fictionalism as developed for one discourse, that of mathematics or number-talk.

1 The position we argue for (conditionally) here thus identifies a rather different relation between T-deflationism and fictionalism about truth than that claimed in certain earlier discussions of alethic fictionalism. Both Beall (2003) and Woodbridge (2005) present their respective fictionalist accounts of truth (or truth-talk) as versions of T-deflationism, in competition with other, nonfictionalist versions of T-deflationism. The central thesis developed here is also different from the conclusion argued for in Armour-Garb \& Woodbridge (2010), which attempts to establish that T-deflationists should endorse specifically a pretense account of truth-talk. The more general position developed here allows T-deflationists a broader range of options within fictionalism about truth and thus is not hostage to objections particular to any specific version of the approach, including the objection that Armour-Garb \& Woodbridge (2010) considers. By contrast, the objections that we take up below are directed at bigger picture concerns regarding a general identification of T-deflationism with fictionalism about truth. Price (2003) also briefly suggests such a general identification (p. 189), but the position we (conditionally) advocate here differs from his views because we do not take such an identification to undermine the very distinction between fictionalism and nonfictionalism, the way Price (Ibid.) does. See endnote 32, for more on this point.

2 Of course not all of the discourse must be problematic, but at least some fragment of the discourse will be. For what follows, please read 'discourse' as, in effect, denoting a fragment of discourse. 


\subsection{Yablo's Figuralism}

In "The Myth of the Seven", Yablo (2005) argues for a fictionalist account of mathematical discourse, one that, if Yablo is correct, would improve upon Hartry Field's (1980, 1989) brand of mathematical fictionalism, given certain reasons for worrying about Field's own account (for some of the worries, see Shapiro (1983) and Yablo (2005), among others). One of the chief premises Yablo offers in support of his fictionalism about number-talk is the thesis of expressive indispensability, viz.,

(EI) We need to enlist certain aspects of X-talk, as a means for expressing certain claims that we could not otherwise express.

According to Yablo (Ibid.), in the case specifically of number-talk, we need to enlist number-terms, which appears to commit us to numbers as objects, as a means for expressing certain claims (to be discussed below) that we otherwise could not-or, at least, could not so easily-express. But what we are trying to say through our use of number-talk has nothing to do with numbers per se and, in fact, but for certain expressive limitations, could be expressed without appeal to numbers at all. Moreover, such expressive needs have nothing to say about numbers - their nature or even their existence - or about whether there even need to be any, in order to use number-terms to express what we aim to convey. So, while number-talk appears to be expressively indispensable, numbers, qua objects, may well be theoretically dispensable.

To make this point, Yablo (ibid., p. 94) considers a case in which a physicist who is studying escape velocity wants to formulate a statement about it that covers an infinity of particular facts about the trajectories of certain objects in particular gravitational fields. In order to be able to express the infinitely many facts in finite fashion, the physicist quantifies over numbers to produce:

(B) For all positive real numbers $\mathrm{M}$ and $\mathrm{R}$, the escape velocity from a sphere of mass $M$ and a diameter $2 R$ is the square root of $2 G M / R$, where $\mathrm{G}$ is the gravitational constant.

What (B) does is gather together, into a single statement, uncountably many facts the expression of which would otherwise require an uncountably infinite number of substitution instances of a schematic statement form. Since it is in principle impossible to write down or assert the uncountably many sentences that we would need to, if we wanted to express certain physical laws or regularities, it seems that we need to be able to quantify over real numbers. But, as Yablo (Ibid.) points out, in this example the physicist appears to invoke numbers for expressive 
reasons only, given that what she is trying to convey has nothing to do with numbers. ${ }^{3}$

In this case, enlisting number terms is advantageous, since it enables the physicist to express the infinitely many facts without requiring an uncountable infinity of sentences, each of infinite length. But to do this, numberterms only need to serve as aids in representing something that neither involves, nor presupposes, the existence of numbers. As Yablo notes, since what the physicist is trying to express has nothing to do with numbers, and since the real existence of numbers would neither help nor hinder understanding of what she is trying to get across, we have no reason to go on to conclude that, therefore, numbers exist.

\subsection{From Truth-Talk to Number-Talk}

Yablo sees, in the expressive role that number-talk affords, an analogy with a T-deflationist's claim about truth-talk. As he (2005, p. 95) notes, on the assumption that the truth-predicate plays a merely expressive role, as a device that facilitates the expression of opaque endorsement towards statements to which we cannot express our commitment directly (say, by just asserting them), there is "[n]o need then to take the truth-predicate ontologically seriously; its place in the language is secured by a role it can fill quite regardless of whether it picks out a property." And, making the connection between a deflationary account of truth and his own view regarding the expressive role of number-talk, he suggests that "[j] ust as truth is an essential aid in the expression of facts not about truth (there is no such property) [according to the T-deflationist], perhaps numbers are an essential aid in the expression of facts not about numbers (there are no such things)" (ibid.).

Yablo (Ibid.) goes on to argue that because a T-deflationist like Field will conclude that there is no reason to take the truth-predicate ontologically seriously, since he sees 'true' as a device that exists purely "to serve a certain logical need" (Cf. Field, 1994, p. 264; 2008, p. 18), Field might have allowed that the same is true of number-terms, if, as Yablo has maintained, number-talk likewise serves an expressive role that it could fill, regardless of whether number-terms actually pick out any objects. Field might thus have concluded that, while number-talk is expressively indispensable, it can fill that role quite regardless of whether number-terms pick out any objects at all (let alone numbers!).

Now, while Yablo argues that, in light of these considerations, Field might have argued for a different sort of fictionalist account of number-talk,

3 Yablo (Ibid.) notes that number-talk is invoked since the facts, if fully expressed without appeal to numbers, would require the introduction-as well as the employment - of uncountably many predicates, together with an uncountable number of sentences of, to make things worse, infinite length. 
it bears noting something that Yablo does not consider, viz., that the considerations that he musters, in support of a fictionalist view of mathematics, if plausible, might likewise motivate a fictionalist view of truth. That is, rather than (or along with) seeing Field's allegiance to the exhaustively expressive role of the truth-predicate as suggesting a Yablo-style fictionalist account of number-talk, T-deflationists might see Yablo's appeal to fictionalism in explaining the exhaustively expressive role of number-talk as suggesting a fictionalist view of truth-talk. Thus, if the impetus for adopting this sort of fictionalist view about some way of talking turns on adopting some kind of expressive stance towards some feature of the discourse, and if Yablo is right about number-talk (and, again, we are assuming that he is), then perhaps we can find compelling reason for endorsing the claim that wouldbe T-deflationists should be fictionalists about truth (or rather, truth-talk). This is what we shall argue, in $\S 3$. Prior to making this case, however, we must first get clearer on deflationism about truth.

\section{Deflationism in General}

Deflationary approaches (or accounts, views, etc.) are usually characterized negatively, by specifying features a given expression lacks. More generally, a deflationary approach will typically accept some discourse or concept without granting certain metaphysical or epistemological presuppositions that are commonly associated with it. Such an approach accepts and explains some fragment of a discourse, while obviating the need for postulating a theory that would require special epistemic access or a putatively dubious metaphysics, while still granting that there is a role or function for that part of the discourse.

Although in the last century much work has been done on truth, there was, at least initially, an assumption - that there is some thing about which we should be theorizing. T-deflationists essentially deny this assumption. That is, they deny that there is something there to theorize about, which is not to say that there is no room for theorizing. One who adopts T-deflationism replaces the traditional question of what truth is with the question of what the expression 'true' does. But she does not attempt to replace an earlier theory of truth with a new one; rather, part of the view involves convincing us that no such theory is needed at all. ${ }^{4}$

4 Stephen Leeds $(1995$, p. 4) takes T-deflationism to be "the simple denial that we need a theory about the relations between language and world." Understood in this way, the chief question that gets raised is whether, with respect to the notion of truth, the philosophy of language is essentially complete, as a T-deflationist about truth will contend, or whether it is still in its infancy on this issue. Leeds's account of what T-deflationism amounts to makes it seem that it is a purely negative thesis, but this is just because he is contrasting T-deflationism with the correspondence theory of truth. 
For our purposes, we may take deflationary accounts of truth to comprise four features, the conjunction of which we will call T-deflationism's core commitment. ${ }^{5}$ One who does not endorse a deflationary view of truth (for example, inflationists, though, of course, not all non-deflationists must be inflationists) denies at least one of the features of the core commitment. These features are as follows: the property thesis, the concept thesis, the term thesis, and the rule thesis. ${ }^{6}$

The property thesis holds that there is no genuinely substantive property of truth, if there is a property of truth at all. ${ }^{7}$ The concept thesis holds that there are no conceptual connections that would, or, indeed, could, serve to elucidate the concept of truth at a more fundamental level. On this view, there are no "deep" connections between the concept of truth and other concepts (e.g., belief, knowledge, assertion, meaning) such that the details of the latter would shed light on the former. According to the term thesis, the expressions 'true' and 'false' serve as devices of semantic descent and are crucial for expressing infinite conjunctions and disjunctions. Finally, the rule thesis holds that the direct use of some putative truth-bearer and an ascription of truth to it are intersubstitutable in all extensional (or "transparent") contexts.

We have said that any view of truth that subscribes to these four theses shall count as a deflationary view of truth. But how are we to understand the relationship between deflationism about truth and a particular deflationary theory, or account, of truth? And what are the important distinctions between, say, disquotationalism and inference-rule deflationism?

Disquotationalists, who take as theoretically basic the instances of the T-schema,

(T) ' $\mathrm{S}$ ' is true iff $\mathrm{S}$,

are properly characterized as $\mathrm{T}$-deflationists, though not all $\mathrm{T}$-deflationists are, or need be, disquotationalists. In addition, Minimalists, who take each (non-pathological) instance of the Equivalence Schema,

5 Our claim is that this core commitment is sufficient, though it need not be necessary, for one to be taken to be a T-deflationist. For more on this core commitment, see ArmourGarb (2012).

6 We should say now that much of what we have said carries over directly to talk about falsity. Hence, T-deflationists typically accept a property, concept, term and rule view for falsity as well.

7 Since we are just setting out the view, we will not have anything to say about what it is for an expression to express a property that is substantive (nor shall we have anything to say about the expression-relation). That said, it is standard to hold that for a property to be substantive is for it to possess an underlying nature. (For a discussion, see Horwich (1998a, Ch. 3; 1998b, Ch. 4).) Of course, if we are happy to allow that some meaningful predicates fail to express any properties at all, then the need to characterize properties as either "substantive" or not may well become otiose. 
(ES) $<\mathrm{p}>$ is true iff $\mathrm{p}$,

(where 'p' serves as a sentential variable that can be replaced by any declarative (English) sentence, and where the angle brackets, ' $<$ ' and ' $>$ ', serve as a device for nominalizing any sentence that goes in for 'p') to be conceptually, explanatorily, and logically fundamental also endorse T-deflationism. ${ }^{8}$ But the same holds for advocates of inference-rule deflationism, whose theory of truth comprises the inference-rules, 'True'-In and 'True'-Out, viz.,

$$
\begin{aligned}
& \text { 'True'-In: } \mathrm{p} \Rightarrow \mathrm{T}(<\mathrm{p}>) \\
& \text { 'True'-Out: } \mathrm{T}(<\mathrm{p}>) \Rightarrow \mathrm{p},
\end{aligned}
$$

where ' $\Rightarrow$ ' can be understood as representing an inference rule, or as capturing a substitution rule, to the effect that, in all extensional/transparent contexts, one can intersubstitute ' $<\mathrm{p}>$ is true' ('p') for 'p' (' $<\mathrm{p}>$ is true').

Now, while a T-deflationist will likely adopt a particular account of truth (or, more precisely, of truth-talk, that fragment of discourse that centers around use of the truth- and falsity-predicates), her doing so is different from her endorsement of T-deflationism. As such, objections peculiar to a given deflationary account of truth, while potentially serious, are not, ipso facto, objections to T-deflationism in general. For this reason, our focus, in what follows here, will be on T-deflationism, understood as a genus, rather than on any of the species of deflationary accounts of truth. ${ }^{9}$

\subsection{The (Actual) Role of 'True'}

As a number of philosophers have pointed out, there are certain cases in which the truth- (and falsity-) predicate seems to be expressively indispensable. For example, consider a 'true'-free theory, $\tau$, understood as a collection of sentences that is not finitely axiomatizable, and say that we are committed to $\tau$. Question: How can we express our commitment to it?

We certainly cannot express our commitment to $\tau$ by asserting singly each of its members. What we want is a device that will enable us to express, in a finite manner, the same commitment that we would express, per impossibile, by singly asserting all of $\tau$ 's members. And, with the truthpredicate, we can do just that-by asserting that all members of $\tau$ are true. Similarly, we can deny a theory, even if we cannot pinpoint which of its particular claims we reject-by asserting that not all members of $\tau$

Horwich (1998a, pp. 121, 126-128, 138).

9 For a comprehensive account of the varieties of T-deflationism, see Armour-Garb (2012). 
are true. ${ }^{10}$ Finally, we can acknowledge the contingency of $\tau$, while expressing commitment to it-by asserting that any member of $\tau$ could have failed to be true (Cf. Field, 1994, p. 265).

T-deflationists and non-T-deflationists alike recognize the truth-predicate's role in completing or performing these expressive tasks. But many T-deflationists have gone further. While they claim, as they should, that, in the case of expressing our commitment to $\tau$, the truth-predicate is facilitating, or aiding in, the expression of opaque endorsement, they go further and claim that the truth-predicate is a device of opaque endorsement, or, sometimes, that it is a device of generalization. A related claim sometimes made is that the truth-predicate is a device of infinite conjunction and disjunction (Ibid., p. 264; Field, 2008, p. 210). But the truth-predicate is not a device of opaque endorsement, nor is it a device of generalization or of infinite conjunction and disjunction. Rather, together with other machinery (notably, quantifiers and variables), the truth-predicate can serve as a device for expressing endorsement (indeed, for expressing opaque endorsement), and it, together with a quantifier, can serve as a device for expressing generalizations or infinite conjunctions and disjunctions. ${ }^{11}$ But if T-deflationists should not identify the truth-predicate with these particular roles, how should they think about that predicate?

We can say something about what kind of device 'true' is if we consider what the truth-predicate has to be like, in order for it to perform the aforementioned roles. Here we endorse a slightly generalized version of the account offered by Quine (1986). In setting out his disquotational account, Quine discusses the role of the truth-predicate in canceling out the semantic ascent achieved by forming the quotation name of a sentence. More generally, what the truth-predicate does is to undo some nominalization of a content-vehicle, where this nominalization can occur in a number of ways. ${ }^{12}$

In addition to forming the quotation name of a sentence, some of the other (familiar) ways of nominalizing a sentence include: forming some structural description of a sentence uttered; forming a 'that'-clause of a sentence that is/could be uttered or that expresses the content of a mental state; offering a definite description of an utterance or mental state; etc. These operations all result in ascent, viz., from the use of a content-vehicle to express that content to a kind of mention of the vehicle. The truth-predicate

10 We reject a given theory when we reject at least one of its claims. But we sometimes wish to express our denial of a theory without knowing which of its claims ought to be denied. When the theory is not finitely axiomatizable, the falsity-predicate (or the truthpredicate, coupled with negation) ends up being expressively indispensable, if we are to express our commitment against the theory.

As Quine (1986) notes, all we need is the truth-predicate and suitable quantifiers, and that will allow us to generalize over a body of claims. 
undoes this ascent to provide something equivalent to the direct presentation of the content that attaches to the content-vehicle.

We will use the expression 'semantic descent' to capture this operation of the truth-predicate in general. Now, being a device of semantic descent is part of what allows the truth-predicate to serve the useful functions that it does. It is a device of semantic descent which, when coupled with other resources (e.g., quantifiers, descriptions, etc.), can be employed to express opaque endorsement, enabling its users to express agreement with (or perhaps indirectly co-assert) a certain body of claims, as might appear, for example, in a theory like $\tau$. In addition, the truth-predicate's function, as a device of semantic descent, also allows it to serve in the expression of infinite conjunctions and disjunctions, in the performance of a kind of "generalizing role". 13

\section{From a Fictionalist View of Number-Talk to a Fictionalist View of Truth-Talk}

Having clarified some basic features of T-deflationism, we now draw the connection between Yablo's considerations in favor of fictionalism about number-talk and analogous ones in favor of T-deflationists adopting fictionalism about truth-talk. In order to make this connection, we will draw a parallel between the expressive advantages of number-talk and those of truth-talk. Having done this, we will go on to show that we can redeploy Yablo's considerations so as to support fictionalism about truth-talk. We will begin by returning to the expressive advantages of number-talk.

\subsection{The Expressive Roles of Number-Talk and Truth-Talk}

As Yablo (2005, pp. 94-5) notes,

To express the infinitely many facts in finite compass, we bring in numbers as representational aids. We do this despite the fact that what we are trying to get across has nothing to do with numbers, and could be expressed without them were it not for the requirement of a finitely based notation.

Now, in order to forge a link between Yablo's argument for a fictionalist view of number-talk and a related one in favor of a fictionalist view of truth-talk, it bears noting that, for a T-deflationist, the very thing that Yablo presses, with respect to number-talk, can also be said about the expressive advantages of truth-talk. Indeed, we might ape his claim as follows:

13 For more on the claim that, for a T-deflationist, the truth-predicate is a device of semantic descent (rather than being a device of generalization, or blind, or opaque, endorsement), see Armour-Garb (2012). 
To express the infinitely many conjuncts (or disjuncts) in a finite compass, we bring in the notion of truth as a representational aid. We do this despite the fact that what we are trying to get across has nothing to do with truth, and could be expressed without truth-talk were it not for the requirement of a finitely based notation.

Put differently, Yablo privileges the expressive utility of number-talk, claiming that, once we see how number-talk functions, as a means for facilitating the expression of facts not about numbers that we cannot (given our finitude) express, we will see that there is no reason to grant the real existence of numbers. He further claims that what it takes to understand number-term-involving statements does not require that we even accept the real existence of numbers. Moreover, given that the tasks that number-talk facilitates are purely expressive, there is no need to take number-talk ontologically seriously, since what enables a number-terminvolving statement to express what it does in no way requires the real existence of numbers.

But a T-deflationist will say the same thing about truth-talk. ${ }^{14}$ Once we see how truth-talk functions, as a means for facilitating the expression of facts (which, in turn, facilitates the expression of our commitment to those facts), which have nothing to do with truth, ${ }^{15}$ we will see that there is no reason to grant that 'true' expresses a "substantive" property (or that it expresses a property at all). A T-deflationist will further claim that what it takes to understand 'true'-involving statements does not require that we even accept the real existence of a property of truth. Moreover, given the expressive tasks that truth-talk facilitates, which are all that T-deflationists will acknowledge, there is no need to take truth-talk ontologically seriously, since what enables a 'true'-involving statement to express what it does in no way requires the real existence of a property of truth. ${ }^{16}$

We have thus drawn a link between the expressive utility of number-talk and that of truth-talk. With the link established, we shall turn to the second consideration, from noting the expressive role of truth-talk to the endorsement of a fictionalist account of truth-talk. Prior to doing so, however, we

As should be clear, T-deflationists can say the same about the falsity-predicate, e.g., that what it takes to understand 'false'-involving statements does not require that we even accept the real existence of a property of falsity. For what follows, we shall stick with truth-talk, though it is important to note that whatever we say about that talk, we can also say about falsity-talk.

Cf. Field (1999, p. 533) on the role of truth-talk in expressing what he calls "fertile generalizations" having nothing to do with truth.

It bears noting that if a substantivist could succeed in undermining the T-deflationist, he would do so by claiming that there is some instance of truth-talk where the use of the truth-predicate really must be taken to attribute such a property, where this appearance cannot be "explained away" via appeal to the truth-predicate's expressive roles. 
will briefly characterize the notion of a "representational aid", which was employed in establishing the aforementioned link.

\subsection{Representational Aids}

Thus far, we have simply relied on Yablo's (2005) brief comments about representational aids, to wit, that making an utterance employing a representational aid involves making as if to talk about one thing for the purposes of talking about something else indirectly. Generalizing slightly beyond the idea just of "thing-talk" representational aids, we also characterized serving as a representational aid as serving in the indirect expression of certain facts by seeming to express other putative facts (alternatively: apparent states of affairs). ${ }^{17}$ In order to clarify the notion of a representational aid, we will begin by considering some common modes of speaking in which indirect expression is already fairly familiar and explain the senses in which performing that indirect expression makes some part of the discourse a representational aid. Having done so, we will then explain the ways in which the truth-predicate appears to function as a representational aid.

To start, consider a common idiom, as might appear in a sentence like

(1) Bob put that project on the back burner.

When we assert (1), certain training with the 'back burner' locution allows us to use it to express facts about the project in question other than those pertaining to its location on a stove. ${ }^{18}$ On a surface-level or "face-value" reading, an assertion of (1) appears to represent certain stove-location states of affairs, but we actually take the expression of certain other (non-stoverelated) states of affairs to be the point of making the assertion. These other states of affairs are somewhat complicated and open-ended, involving such elements as Bob moving his attention away from the project in question to focus on something else, while still not considering Bob (to take himself) to be finished with the project in question, along with thinking that Bob will (or: plans to) resume focusing on that project again in the future, has not abandoned the project, etc. Explaining the status of Bob's project directly would be somewhat long-winded and would, inevitably, also involve

17 We do not have in mind any particular view about states of affairs and intend them in the most benign sense - as ways things could be. So, for example, we might say that the state of affairs that gets expressed by an assertion of 'Isabel loves Zev' is just Isabel loving Zev. Talk of states of affairs (like that of apparent "facts") can raise some thorny issues (e.g., negative states of affairs). Since we are not resting anything on either the proper analysis of, or even the real existence of, so-called "states of affairs" (or: "facts"), we can leave any such thorny issues aside.

18 Idioms are especially interesting here, since it is not entirely clear that they involve explicitly figurative discourse. For more on idioms, see Egan (2008). 
subtleties that can be difficult to express. The 'back burner' idiom avoids the long-windedness, permitting the expression of all of this in a quick, easy (and colorful) way. In so doing, it serves as an aid in the expression (or: the representation) of more complicated states of affairs, by appearing on the surface to express some other, simpler state of affairs. We can thus see the "expressive advantage" of the exploitation of idioms - as an indirect way of expressing certain states of affairs that might be more difficult to express directly.

In the case just considered, the surface-level, apparently represented state of affairs is a locution-independent, potentially real situation that gets expressed on the surface of the assertion by means of the central locution at work. While this seems to hold in many, if not all, cases of idiomatic discourse (and ditto for many cases of metaphorical discourse), there are also fragments of discourse in which the states of affairs that are apparently expressed (on a surface reading of the sentence asserted) cannot be taken as a locution-independent, potentially real situation.

As an example of this latter sort of case, consider an assertion of a sentence such as

(2) Mary came to the party only for Bob's sake.

On a direct, face-value reading of an assertion of (2), the use of the locution 'sake' seems to function in the expression of what we might call a sake-involving state of affairs. As a result, it appears to commit the speaker to the existence of sakes. But there are no such things (ex hypothesi), and, as a consequence, there are no potentially real, sake-involving states of affairs. There are no uses of the 'sake' locution for which "sakes" are the real point. Thus, what 'sake'-talk seems to express on the surface, e.g., what a face-value reading of (2) seems to yield (certain sake-involving states of affairs), is even further removed (in the sense of not even being potentially real) from the states of affairs that the expression actually serves to represent.

The states of affairs that 'sake'-talk actually serves to represent are of a different and more complicated sort; and the point of 'sake'-talk is to operate as an aid in expressing them. The talk seems to provide a neat and simple means for indirectly expressing some possibly complex states of affairs that involve various interconnected elements, including, at the very least, things like someone's welfare, his interests, his emotional states, and a range of relations between them. Thus, as with the idiom case involving (1), the central locution here also serves as a sort of expressive aid, contributing to the indirect representation of some rather complicated states of affairs in a concise, easy way. It does this by operating in (2) to make it appear, "on the surface", that the speaker who assertorically utters (2) 
expresses some simpler state of affairs, to wit, some sake-involving states of affairs. In short, what we mean, by claiming that certain expressions function as "representational aids", is that (presumably via various mechanisms, though we shall have nothing to say about those in this paper) when they occur in some sentences, they aid in the expression of states of affairs other than those that the sentences asserted appear to represent on the surface. Moreover, we take it that at least one important role for expressions that serve as representational aids is that they facilitate the indirect expression of certain states of affairs that cannot be easily expressed directly.

Having clarified, to some extent, the notion of a representational aid, we return to Yablo, in order to forge an important argument parallel.

\subsection{Drawing the Argument Parallels}

Yablo (2005) claims that one of the reasons for adopting fictionalism about number-talk is this. First, say that we can explain the expressive advantage of appealing to number-talk, viz., to "bring in numbers as representational aids", and suppose, further, that these expressive purposes exhaust our use of that talk to say anything about the world. Suppose, finally, that what we are trying to get across through our use of number-talk is not about numbers, in the sense that what we aim to convey itself has nothing to do with numbers. In that case, because number-terms - in number-talk-serve essentially in the indirect expression of facts that are not about numbers, Yablo contends that we should recognize that the talk accomplishes this feat through the operation of fiction. Functioning as a representational aid in this way-making as if to represent one thing for the purposes of representing something else, indirectly-just $i$ s to operate via some element of fiction.

Now, we are assuming that Yablo is right that if number locutions operate as representational aids, then we have a compelling reason for concluding that number-talk operates through some element of fiction. Accordingly, in order to resist Yablo's conclusion, regarding the proper stance to take with respect to number-talk, the burden of proof is on the realist, who must deliver at least one statement in which number-terms serve essentially in the expression of facts that really are about numbers. If none is forthcoming, we have a reason for endorsing fictionalism about number-talk. ${ }^{19}$

We can make a parallel argument, given certain assumptions about how truth-talk functions. First, say that we can explain the expressive advantages

19

One might object, claiming that if no statement is forthcoming in which number-terms serve in the expression of facts that are about numbers, then all that this shows is that we have a reason for endorsing some sort of an anti-realist account. That may be true. But remember that the considerations that we are adducing are Yablo's and, for him, if no such statement is forthcoming, we have a reason for endorsing — indeed, for adopting — a fictionalist view of that talk. 
of appealing to truth-talk, and suppose, further, that these expressive purposes exhaust our use of that talk. Suppose, finally, that what we are trying to get across through our use of truth-talk is not about any property of truth in the sense that what we aim to convey itself has nothing to do with any such property. In that case, because 'true' - the notion, as it occurs in truth-talk - serves essentially in the indirect expression of facts that are not about truth, it functions as a representational aid (in Yablo's sense) and thus operates through some element of fiction. In order to resist this conclusion, the burden of proof is on the objector, who must deliver at least one statement in which truth-talk plays an essential role in the expression of facts that really involve truth. That is, to resist this line of thought, she must deliver at least one statement in which 'true' appears and in which the use of 'true' does not serve a merely expressive role, but instead operates essentially in the expression of facts that really involve a property of truth. If none is forthcoming, we have a reason for endorsing fictionalism about truth-talk. ${ }^{20}$

Notice that the initial assumptions that drove the parallel (viz., regarding the exhaustively expressive role of 'true') just are the claims accepted by T-deflationists, regarding the actual functioning of the truth-predicate. Tdeflationists acknowledge the expressive indispensability of truth-talk, but they do not then go on to conclude that the truth-predicate is "ontologically serious". Rather, they hold that the truth-predicate functions as a device that allows speakers to talk indirectly about something else, facilitating the expression of facts that are not about truth. Accordingly, in order to resist T-deflationism, the burden of proof is on the T-inflationist (or T-substantivist), who must deliver at least one statement in which truth-talk plays an essential role in the expression of facts that really involve truth. ${ }^{21}$ That is, to resist $\mathrm{T}$-deflationism, the $\mathrm{T}$-inflationist must deliver at least one statement in which 'true' appears and in which the use of 'true' does not serve a merely expressive role, but instead operates essentially in the expression of facts that really involve a substantive property of truth. If none is forthcoming, we have a reason for endorsing T-deflationism. ${ }^{22}$

One might object, claiming that if no statement is forthcoming in which some truth-locution serves in the expression of facts that really involve truth, then all that this shows is that we have a reason for endorsing some sort of an anti-realist account of truth-talk. That may be true. But remember that the considerations that we are adducing are Yablo's and, for him, if no such statement is forthcoming, we have a reason for endorsing - indeed, for adopting - a fictionalist view of that talk.

One might further claim that, in order to ensure that the property of truth is substantive (not etiolated, as some T-deflationists" "thin" notion of the property is), there must be a 'true'-involving sentence, $\mathrm{S}$, whose truth-value turns on whether 'true', as it functions in $\mathrm{S}$, expresses a property that is possessed by the object that $\mathrm{S}$ 's referring expression putatively denotes. 
Whatever one thinks about the prospects for T-deflationism, our point here is that, in their dispute with T-inflationists, T-deflationists characterize the role of the truth-predicate in a manner akin to the way Yablo describes the role of number-terms in his argument, viz., as a representational aid. We can see this at work in T-deflationism when we consider that, from a "sentence-level" perspective, the surface form of any instance of truth-talk makes it appear that the truth-predicate serves to do something other than perform a merely expressive role. In our inferential and linguistic practices, 'is true' appears to function predicatively. On analogy with other predicative fragments of discourse, it therefore seems, at least on the surface, to represent a state of affairs that involves some object having or lacking the putative property that the predicate appears to express. In particular, then, in paradigmatic cases of truth-talk (and we think, for example, of "blind" or of quantificational ascriptions of 'true'), this locution appears to serve in the expression of truth-involving states of affairs - ones that involve a property of truth.

Of course, T-deflationists will deny that the truth-predicates actually does what it appears on the surface to do, since they will maintain that, really, there are no truth-involving states of affairs of any sort. Moreover, they will deny that the point of employing the locution is to express any truth-involving states of affairs. They will point out that in such truth-attributions, the truth-predicate is always functioning as a means for indirectly expressing non-truth-involving states of affairs. As in the case of sakes, truth is never the point, and, as with instances of 'sake'-talk, what is apparently expressed on the surface of an instance of truth-talk (viz., some truth-involving state of affairs) is not even a potentially real, locution-independent, state of affairs.

The particular task that T-deflationism takes the truth-predicate to perform is semantic descent. The locution performs this operation on nominalizations of sentential content-vehicles. These nominalizations are the expressions that, in the instances of truth-talk, appear to pick out the objects about which truth-talk seems, on its surface, to express truth-involving states of affairs. But the truth-predicate's semantic descent function of "denominalizing" a sentence nominalization converts the nominalization's mention of a sentence into something content-equivalent to a use of that sentence, thereby effecting the expression of the states of affairs that such a use would express directly. The more interesting instances of truth-talk are those that do not involve a "transparent" nominalization of some content-vehicle, but instead effect "blind" ascription (or quantificational ascription). In such cases, the denominalization effected yields something more complicated.

Consider, for example, what a T-deflationist would say about the operation of the truth-predicate in a blind ascription, as in an assertoric utterance of 
(3) What Bob said is true.

On one standard reading, this sentence is, or amounts to, a compressed quantificational claim of the form

(4) There is some $x$, such that Bob said $x$ and $x$ is true.

T-deflationists will analyze the operation of the truth-predicate in a claim like (4) in terms of its central role of performing semantic descent on nominalizations of sentential content-vehicles. Since such nominalizations (which we can symbolize with ' $<\mathrm{p}>$ ', understood as explained above) can also be taken to pick out the things that Bob can say, T-deflationists will understand uses of (4) as a means for expressing something along the lines of

(5) For some $<\mathrm{p}>$, Bob said $<\mathrm{p}>$, and $\langle\mathrm{p}>$ is true.

Now, since what semantic descent does is to undo the nominalization of some nominalized content-vehicle, thereby effecting the use of the contentvehicle's content, the real point of (5) (and thus of (3)), according to T-deflationists, is the expression of something we might try to capture with the quasi-formal sentence schema

(6) For some $\mathrm{p}$, Bob said $<\mathrm{p}>$ and $\mathrm{p}^{23}$

However, because (6) involves schematic variables for sentence-in-use positions (in its second conjunct) and a substitutional quantifier, the closest we could come in natural language, without employing the truth-predicate (as in (5)), to expressing what we want to cover with (6), would require reeling off an infinite disjunction along the lines of

(7) Either Bob said that crabapples are edible and crabapples are edible, or Bob said that the moon is made of cheese and the moon is made of cheese, or Bob said that corporations are not people and corporations are not people, or Bob said that birds are dinosaurs and birds are dinosaurs, or Bob said that 2 is the only even prime number and 2 is the only even prime number, or... ${ }^{24}$

In this way, what an assertoric utterance of (3) enables a speaker to express indirectly is a commitment to certain complicated non-truth-involving states of affairs, the direct expression of which would require something like (7).

23 Cf. Ibid., p. 264 on T-deflationism taking a claim like (3) to express something like what we want to express with (6). an infinite disjunction of all of its instance. 
But this is to say that, for T-deflationists, in an assertion of (3), the truthpredicate, as it occurs in that sentence, aids in the representation of such complicated non-truth-involving states of affairs, allowing speakers to express, in an easy and finite way, something complicated (and not involving any property of truth) that they otherwise could not express at all, given their finitude.

Now, a T-deflationist will contend that since the immediate function of the truth-predicate is just to effect semantic descent, the truth-predicate itself does not express anything at all and, a fortiori, does not express any property of truth. ${ }^{25}$ Moreover, while she will maintain that the operation of the truth-predicate, in instances of truth-talk, does make the putative truth-attribution perform the task of expressing - indirectly - certain states of affairs, she will also point out that such states of affairs do not in any way involve a property of truth. Put in the vocabulary that we favor, it is a central point of T-deflationism that serving this role makes the truth-predicate serve as an expressive aid, allowing speakers to express (and, thus, to represent) states of affairs that they otherwise would not be able to express.

So, although the truth-predicate seems on the surface to serve in the direct expression precisely of truth-involving states of affairs, T-deflationists will maintain that the truth-predicate serves only in the indirect expression of states of affairs that do not involve any property of truth. But, as we have seen, that sort of indirect "not what it seems on the surface" expressive functioning - in the service of making it possible (or at least a lot easier) to express certain complicated states of affairs - is really all that is involved in a locution serving as a representational aid. That a T-deflationist will point to semantic descent in explaining what the truth-predicate does directly in no way precludes our claim that, for T-deflationists, the truth-predicate functions as a representational aid. In fact, we might go even further and claim that it is in virtue of the truth-predicate's role, as a device of semantic descent, that it ends up functioning as a representational aid.

Given T-deflationists' understanding of the role of the truth-predicate, they should see it as always serving as a representational aid in the way just explained, since they (Cf. Field, 1999, p. 533) contend that it always functions as a device that enables speakers to express something that is not 'true'-involving about something that has nothing to do with any property of truth. Now, if Yablo is right, that whenever certain locutions of a given discourse function as representational aids, that discourse operates in virtue of some element of fiction, then, given what we have seen, it follows that T-deflationists should conclude that the functioning of truth-talk involves an resenting a property, they will also deny that the truth-predicate itself indirectly expresses something different from what it appears on the surface to express directly. 
element of fiction. Put differently, if Yablo is right about number-talk, then T-deflationists should understand truth-talk to function through the operation of a fiction. Given that we are assuming that Yablo's reasoning compels with respect to number-talk, it follows that T-deflationists should endorse or adopt a fictionalist account of truth-talk.

\section{Objections/Responses}

Having made our case, in this section we raise and respond to two possible objections to our claim, viz., that if Yablo is right that philosophers of mathematics ought to adopt a fictionalist view about number-talk, then we have a compelling reason for holding that T-deflationists ought to adopt a fictionalist view about truth-talk.

\section{1a. Objection One}

It seems reasonable to employ the notion of fiction if, as Yablo argues, we can see number-talk as playing an entirely expressive role. This is because number-locutions appear to be ontologically committing. But even if we can see truth-talk in terms of an expressive device, it seems clear that truthlocutions, being predicates, do not appear to be ontologically committing. As such, while it may be reasonable to endorse a fictionalist account of number-talk, the reasons for this do not carry over in support of understanding deflationism in terms of fictionalism about truth-talk. ${ }^{26}$

\section{1b. Response to Objection One}

We have tried to show that if we were to grant Yablo's considerations in favor of a fictionalist account of number-talk, then, for T-deflationists, those very considerations can be employed as a means for supporting a fictionalist account of truth-talk. The going objection points to a supposed dissimilarity between number-talk and truth-talk and uses that as a means for denying that the reason for adopting a fictionalist view of number-talk carries over in support of a fictionalist view of truth-talk (even assuming T-deflationists are right about the expressive role of truth-talk). In particular, the objection claims that numberlocutions, as singular terms, appear to be ontologically committing, while the truth-locutions, as predicates, do not appear to be ontologically committing.

Now, we might grant that some instances of number-talk appear to be ontologically committing, in virtue of the fact that certain uses of numberlocutions appear to refer to objects, while also granting that, at least in perhaps the most central uses of truth-locutions, they do not appear to refer 
to any objects at all. So, we might grant that truth-talk does not appear to be ontologically committing in exactly the way that number-talk does. But it certainly does not follow that none of the truth-locutions appears to be ontologically committing. Indeed, as we will show, some common uses of some of them do appear to be ontologically committing, which shows that the going objection must be rejected.

To see an example of this, consider the familiar slogan that belief aims at truth. In offering this gloss on the nature of belief, we seem committed to there being something at which it aims - something that the term 'truth' denotes and which the term 'true' expresses. Similarly, certain non-T-deflationists, following Dummett (1959) (and, more recently, Priest (2006)), endorse a teleological account of truth the central thesis of which is that truth is the aim of assertion. Leaving aside the issue of whether an account of this sort is acceptable (or whether it is properly characterized as "nonT-deflationist"), this central thesis appears to capture something important about assertion. And in doing so, it appears to commit us to something, viz., that at which assertions ought to aim.

Whether these 'truth'-involving claims about belief and assertion have substantive or non-deflationary consequences is irrelevant, for present purposes. What matters here is (i) that each of these 'truth'-involving statements appears to be ontologically committing, and (ii) that, in all such cases, T-deflationists will claim that the truth-locution employed still serves just as an expressive device (or, as we would describe things, as a representational aid).

To resolve the tension between these points, the T-deflationist will begin by noting that both the claim that belief aims at truth and that truth is the aim of assertion are normative, telling us what we should (or should not) do. ${ }^{27}$ As such, the claim about belief's or assertion's aim or telos can be read as saying something like

(a) You should believe/assert something only if it is true.

In turn, (a) enjoins us to believe/assert that snow is white only if, actually, snow is white; to believe/assert that grass is magenta only if, actually, grass is magenta; etc. ${ }^{28}$ To be sure, it seems that we cannot dispense with a

27 Interestingly, Price (2003) maintains that the normative function of the notion of truth is something that T-deflationism (which he understand centrally in terms of a disquotational view) cannot account for, whereas his fictionalism about truth, an approach he sees as an alternative to T-deflationism, can. Thus, on his view, the normative consideration blocks an identification of T-deflationism with fictionalism about truth. As we discuss below, we do not think T-deflationism is so hamstrung with respect to accounting for the normative role of 'true'. 
truth-locution here, given the language that we are employing. But such an expression is merely serving as an aid for expressing something that neither involves nor presupposes a property of truth.

Notice that a norm such as (a) also yields

(b) If something is not true, then you should not believe/assert it.

This norm, in turn, enjoins us not to believe/assert that snow is green, if snow is not green, not to believe/assert that grass is magenta, if grass is not magenta, etc. Moreover, if one does not know that she should not believe/ assert that snails are toxic unless snails are toxic and, more generally, if she does not know that she should not believe/assert something unless it is true, we would judge that person to be (semantically) incompetent with the concepts of belief and assertion. In that case, where we would judge a speaker to be semantically incompetent, we enlist the truth-predicate because of our expressive limitations. But notice that we would not-at least we would not obviously, given our teleologist's main statement-be relying on a property of truth, in order to be justified in so judging. ${ }^{29}$

This is enough to show that the going objection fails. Here is why. The objector contends that even if it is reasonable to employ a fictionalist account of number-talk, on the assumption that number-locutions function as expressive devices, although they appear to be ontologically committing, the same cannot be said of truth-talk. That is, the objector grants that T-deflationists maintain that truth-locutions function just as expressive devices but denies that they are (or: that they appear to be) ontologically committing. From this, he concludes that the reasons in support of a fictionalist view of number-talk do not carry over (assuming T-deflationism) in support of a fictionalist view of truth-talk. But we have just seen cases of truth-talk in which truth-locutions function as expressive devices but appear, nevertheless, to be ontologically committing. Thus, contrary to what the objector contends, the reasons for endorsing fictionalism about number-talk do carry over in support of fictionalism about truth-talk.

If one does not find the reply just offered convincing (perhaps because she thinks that, especially for a T-deflationist, the prima facie ontologically committing truth-locutions fail to be genuinely committing or she thinks they are derivative rather than central), there is another response to the first objection that is available-one that is entirely methodological. The response is as follows. that notion. But that is an issue for another paper. 
We can grant that there may be some dissimilarities between number-talk and truth-talk, but we should go on to note that, in his argument for why we ought to endorse fictionalism about number-talk, Yablo does not rely on the aspect of that talk that might be held not to be present in the case of truthtalk. That is to say, even if there are some dissimilarities, those aspects of number-talk not present in truth-talk are not "operative" in Yablo's argument for a fictionalist account of number-talk. As a result, even if there are some differences between number-talk and truth-talk, this does not affect our argument, to the effect that if Yablo's considerations in favor of a fictionalist account of number-talk compel, then T-deflationists should endorse, and adopt, a fictionalist account of truth-talk. In order to see why this response adequately addresses the objection, let us return to Yablo's chief contention.

Yablo (2005, p. 95) argues that because the expressive role of numbertalk has it serving as "an essential aid in the expression of facts not about numbers (there are no such things)," we have a reason for endorsing, or adopting, a fictionalist account of that talk. At base, our claim is that if we grant Yablo's (Ibid.) contention, then, because T-deflationists hold that truth-talk functions as an essential aid in the expression of facts not about truth (there is no such property), we have a reason for endorsing, or adopting, a fictionalist account of that talk. Accordingly, if we assume that Yablo's considerations in favor of a fictionalist account of number-talk compel (and, again, for purposes of this paper, we assume that they do), then T-deflationists have an impetus for endorsing, and adopting, a fictionalist account of truth-talk. And this is so, even if there are some differences between number-talk and truth-talk. ${ }^{30}$

\section{2a. Objection Two}

In general, philosophical fictionalism about a region, or fragment, of discourse, D, is committed to the view that the sentences of D are not literally true. As such, fictionalists about truth-talk will have to maintain that the 'true'-involving sentences of that discourse are not literally true. But then it seems to follow that, on a fictionalist account of that talk, although an utterance of 'snow is white' will be deemed correct, an utterance of " snow is white' is true" will not be deemed correct. This would be a problematic result for any account of truth, but it seems especially problematic for a T-deflationist, since if 'snow is white' is correct (and assertible), while an ascription of truth to it is not, it seems that we shall have to take the two sentences quite differently. ${ }^{31}$

\footnotetext{
30 Thanks to an anonymous referee for suggesting that we clarify this response to the current objection.

31 Thanks to an anonymous referee for raising this objection.
} 


\section{2b. Response to Objection Two}

The objection appears to reveal an incompatibility between certain aspects of T-deflationism (which were touched on in \$2) and certain alleged features of philosophical fictionalist accounts. More specifically, given T-deflationists' adherence to a sort of equivalence (at the very least, in truth-value), between a content-vehicle and an ascription of truth to that vehicle, if fictionalist accounts of truth-talk will require that in some sense we deny that equivalence (e.g., by treating the two claims differently), then perhaps T-deflationists ought not, and in fact cannot, embrace philosophical fictionalism about truth-talk. In particular, the objection assumes that all philosophical fictionalists are error theorists, maintaining that the sentences of D are literally false, and goes on to note that this raises doubts about the plausibility of combining deflationism about truth with a fictionalist view of that talk. ${ }^{32}$

Now, it is correct that, in one way or another, each of the myriad strands of philosophical fictionalism will maintain that the sentences of a relevant discourse are not literally true, but that claim is ambiguous in a crucial way. The initially proposed fictionalist accounts, e.g., those put forward by Field (1980, 1989), with respect to mathematical discourse, Rosen (1990), with respect to modal discourse (regarding possible-worldstalk), and perhaps Mackie (1977), with respect to moral discourse, were error-theoretic in the traditional sense. Such theorists-notably Field (Ibid.) - held that while the existence-implicating sentences of D are not literally true, they are still good and worth uttering, since making as if they are true (or: correct; or: acceptable) can be useful for theoretical reasons. But not all philosophical fictionalists are error-theorists in that sense. $^{33}$

Certain more recent fictionalist accounts employ a pretense-involving fictionalism - as developed in Walton (1990), Crimmins (1998), Kroon (1996, 2004, 2005, 2009), and Yablo (1996, 2000, 2001, 2005) (and, in a

32 This "error-theoretic assumption" is also the basis of the worry that Price (2003) considers, regarding a possible collapse of the fictional-nonfictional distinction that fictionalism about truth might yield, raising the question of whether it is even possible to "formulate a meaningful...fictionalism about the semantic terms themselves" (p. 188). We maintain that Price's concern on this front dissolves for the same reason that the present objection dissolves, namely because fictionalism about truth need not involve the "error-theoretic assumption".

To be sure, as Nolan, Restall \& West (2005) point out, when discussing a fictionalist account of moral discourse, "[t]he simplest fictionalist approach to a discourse takes certain claims in that discourse to be literally false ... ." But, first, this does not say anything about all of the sentences of the relevant discourse, and, second, it makes clear that this is but one fictionalist approach. Note, as well, that Field (1989) also acknowledges other possibilities. 
different sense, Evans (1982)) — that should not be read as error-theoretic. ${ }^{34}$ According to them, an utterance of a sentence from a pretense-involving discourse, D, can still express some content about the real world indirectly, though any such content will be different from what the sentence appears, on its surface, to say. On such an account, the postulation of pretense at work in the sentences of D involves maintaining that the content of an utterance so understood - the serious content of such an utterance-should not be determined by a "face-value" reading of the sentence. ${ }^{35}$ As a result, the serious content of such an utterance can be true even if the sentence, taken literally, would not be true.

So, both species of philosophical fictionalism will grant that sentences of the relevant discourse are "not literally true". But some-the error-theoretic fictionalists-will hold that those sentences are therefore literally not true, while others - the pretense-involving fictionalists - will hold that while the sentences would not be true, if literally construed (if they can be literally construed at all), the serious content of what they express can, in fact, be true.

This is enough to show that there is a problem with the going objection, as it shows its assumption to be false: Philosophical fictionalists need not be error theorists about the sentences of their respective discourses. As such, philosophical fictionalists about truth-talk need not grant that while 'snow is white' is true, an ascription of truth to it is not.

The current objection is launched at the dictates of a particular species of fictionalist accounts of truth-talk: error-theoretic accounts. While we have argued that if Yablo is right then there is a reason for T-deflationists to adopt fictionalism about that talk, in our argument we neither rely on, nor aim to support, the species of philosophical fictionalism targeted in the objection. Hence, the objection is misdirected, and, when its real target (or

See our (2009), (2012), and (2014) for more on the distinction between error-theoretic fictionalism (ETF) and pretense-involving fictionalism (PIF). This distinction within philosophical fictionalism correlates in some ways with the distinction between revolutionary and hermeneutic fictionalism, respectively. (The distinction within fictionalism was introduced by Stanley (2001), but has its roots in Burgess and Rosen (1997).) Roughly put, read revolutionary fictionalism as the view that we ought to revise our understanding of the statements belonging to the discourse and now take them in a fictional spirit. By contrast, read hermeneutic fictionalism as a thesis regarding actual discourse, viz., that we actually do make statements belonging to that discourse in a fictional spirit. The difference matters because, even if all revolutionary fictionalists are error-theorists, the same is not true of hermeneutic fictionalists. Some, like Yablo (2005), maintain that in virtue of the "serious content" an utterance of the relevant discourse has, it can still turn out to be true. what the sentence, when uttered, says when it is understood from within the pretense it involves. For more on the details behind pretense accounts (together with a comparison with error-theoretic fictionalist views) see our (2014). 
targets) is (are) made clear, it should not be seen as an objection either to the primary thesis of this paper or, really, to the adoption of some sort of philosophical fictionalism about truth-talk. ${ }^{36}$

\section{Concluding Remarks}

Our starting point was Yablo's contention that there need not be any numbers for number-talk to serve useful, if not crucial, expressive purposes. He explains number-terms as expressions that provide speakers with a way to talk indirectly about facts that have nothing to do with numbers, and concludes from this that we should adopt a fictionalist account of number-talk.

Extending Yablo's recognition of the similarities between his take on number-talk and T-deflationists' claims about truth-talk, we re-directed his observation to T-deflationism, in order to link that general conception of truth-talk to fictionalism about truth-talk. As we saw, T-deflationists can explain truth-locutions as expressions that provide speakers with a way to talk indirectly about facts that have nothing to do with truth. Accordingly, if Yablo's considerations in favor of mathematical fictionalism compel, then it seems that there is a reason for $\mathrm{T}$-deflationists to endorse fictionalism about truth-talk.

What we have not done is to explain how the central expressions of truth-talk manage to fulfill their expressive functions, for explaining that would require the presentation of a particular account of that talk from the appropriate species of philosophical fictionalism. In fact, we do favor a particular fictionalist account of truth-talk. ${ }^{37}$ But the arguments that we have presented in this paper neither rely on, nor determine, any particular fictionalist account of truth-truth as being the one that one ought to endorse in the service of T-deflationism. As such, we leave a discussion of the formulation of such an account for another time. ${ }^{38}$

\section{References}

Armour-Garb, B. 2012. 'Deflationism (About Theories of Truth)'. Philosophy Compass 7, pp. 267-277. and Woodbridge, J. (2010) 'Why Deflationists Should be Pretense Theorists (and Perhaps Already are)', in N. Pedersen and C. Wright

In support of this, recall the point made previously (§2), viz., that objections peculiar to a given deflationary theory of truth, while potentially serious, are not, ipso facto, objections to T-deflationism in general. An analogous point can be made here at the species level, viz., that objections peculiar to a particular species of fictionalism about truth-talk are not, ipso facto, objections to truth-theoretic fictionalism. For the full presentation of our view, see Armour-Garb \& Woodbridge (2014). and two anonymous referees for their insightful comments and criticisms. 
(eds.), New Waves in Truth, (Basingstoke and New York: Palgrave Macmillan), pp. 59-77.

(2012) 'The Story about Propositions', Noûs 46, pp. 635-674.

(2014) Pretense and Pathology, (Cambridge: Cambridge University

Press, forthcoming).

Beall, JC (2003) 'True and False-As If', in G. Priest, JC Beall and B.

Armour-Garb (eds.), The Law of Non-Contradiction: New Philosophical

Essays, (Oxford: Oxford University Press), pp. 197-215.

Burgess, J. and Rosen, G. (1997) A Subject With No Object: Strategies for Nominalistic Interpretation of Mathematics, (Oxford: Oxford University Press).

Crimmins, M. (1998) 'Hesperus and Phosphorus: Sense, Pretense, and

Reference', Philosophical Review 107, pp. 1-48.

Dummett, M. (1959) 'Truth', reprinted in Truth and Other Enigmas,

(Cambridge, MA: Harvard University Press, 1978), pp. 1-24.

Egan, A. (2008) 'Pretense for the Complete Idiom', Noûs 42, pp. 381-409.

Evans, G. (1982) 'Existential Statements', in J. McDowell (ed.), Varieties of Reference, (Oxford: Clarendon Press), pp. 343-69.

Field, H. (1980) Science without Numbers: a Defense of Nominalism, (Princeton: Princeton University Press).

_ (1989) Realism, Mathematics and Modality, (Oxford: Basil Blackwell). (1994) 'Deflationist Views of Meaning and Content', Mind 103, pp. 249-85.

_ (1999) 'Deflating the Conservativeness Argument', Journal of Philosophy 96, pp. 533-540.

(2008) Saving Truth from Paradox, (Oxford: Oxford University Press).

Horwich, P. (1998a) Truth, Second Edition, (Oxford: Clarendon Press).

_ (1998b) Meaning, (Oxford: Oxford University Press).

Kroon, F. (1996) 'Characterizing Non-Existents', Grazer Philosophische Studien 51, pp. 163-193.

- (2004) 'Descriptivism, Pretense, and the Frege-Russell Problems', Philosophical Review 113, pp. 1-30.

— (2005) 'Belief about Nothing in Particular', in M. Kalderon (ed.), Fictionalism in Metaphysics, (Oxford: Oxford University Press), pp. 178-203.

(2009) 'Existence in the Theory of Definite Descriptions', Journal of Philosophy 106, pp. 365-389.

Leeds, S. (1995) 'Truth, Correspondence, and Success', Philosophical Studies 79, pp. 1-36.

Mackie, J. (1977) Ethics: Inventing Right and Wrong, (London: Penguin Press).

Nolan, D., Restall, G. and West, C. (2005) 'Moral Fictionalism Versus the Rest', Australasian Journal of Philosophy 83 (3), pp. 307-30. 
Quine, W. (1986) Philosophy of Logic, Second Edition, (Cambridge: Harvard University Press).

Price, H. (2003) 'Truth as Convenient Friction', Journal of Philosophy 100, pp. 167-190.

Rosen, G. (1990) 'Modal Fictionalism', Mind 99, pp. 327-54.

Shapiro, S. (1983) 'Conservativeness and Incompleteness', Journal of Philosophy 80, 521-531.

Stanley, J. (2001) 'Hermeneutic Fictionalism', Midwest Studies in Philosophy 25: Figurative Language, pp. 36-71.

Walton, K. (1990) Mimesis as Make-Believe, (Cambridge, Mass.: Harvard University Press).

Woodbridge, J. (2005) 'Truth as a Pretense', in M. Kalderon (ed.), Fictionalism in Metaphysics, (Oxford: Oxford University Press), pp. 134-177.

_ and Armour-Garb, B. (2009) 'Linguistic Puzzles and Semantic Pretense', in S. Sawyer (ed.), New Waves in Philosophy of Language, (Basingstoke and New York: Palgrave Macmillan), pp. 250-284.

Yablo, S. (1996) 'How in the World?' Philosophical Topics 24, pp. 25586.

(2000) 'A Paradox of Existence', in A. Everett and T. Hofweber (eds.), Empty Names, Fiction, and the Puzzles of Non-Existence, (Stanford: CSLI Publications), pp. 275-312.

(2001) 'Go Figure: a Path through Fictionalism', Midwest Studies in Philosophy 25: Figurative Language, pp. 72-102.

(2005) 'The Myth of the Seven', in M. Kalderon (ed.), Fictionalism in Metaphysics, (Oxford: Oxford University Press), pp. 88-115. 